\title{
A aprendizagem significativa no ensino superior: o uso de mapas conceituais na formação do professor de geografia
}

\author{
Significant learning in higher education: the use of conceptual maps in the \\ training of the professor of geography
}

\author{
Ricardo Lopes Fonseca'; Rosana Figueiredo Salvi"
}

\section{RESUMO}

O objetivo da pesquisa consiste em verificar se os estudantes em formação inicial, do curso de Geografia, da Universidade Estadual de Londrina, localizada no estado do Paraná (Brasil), matriculados no $3^{\circ}$ ano ( $6^{\circ}$ semestre) atingem a aprendizagem significativa por meio da construção de mapa conceitual. O mapa conceitual é uma ferramenta que permite ao docente realizar mediação no processo de ensino e de aprendizagem dos seus estudantes. Com a construção de mapas conceituais por meio da Teoria da Aprendizagem Significativa, o professor pode preparar e organizar aulas, fazer a avaliação da aprendizagem e ter o feedback acerca da prática docente. O processo de aprendizagem significativa leva em conta o conhecimento prévio do discente; a disposição para aprender; e, o modo como os conteúdos se ajustam aos problemas de interesse pessoais dos estudantes. No decorrer da disciplina de Metodologia de Pesquisa para o Ensino de Geografia, foi realizada uma oficina sobre mapas conceituais utilizando, como conteúdo exemplificador, a Didática da Geografia. Em grupos os graduandos construíram coletivamente um mapa conceitual referente ao conteúdo ministrado. Por fim, percebeu-se que o mapa conceitual é uma ferramenta que possibilita ao docente realizar de forma facilitadora o processo da aprendizagem significativa.

Palavras-chave: Aprendizagem Significativa; Didática da Geografia; Formação de Professor de Geografia; Mapas Conceituais

\section{ABSTRACT}

The objective of this research was to determine whether students in initial training, Geography course, the State University of Londrina, in the state of Paraná (Brazil), enrolled in the 3rd year (6th semester) reach meaningful learning through building conceptual map. The conceptual map to be a significant learning tool allows the teacher to conduct mediation in the teaching and learning of their students. With construction of concept maps (Novak) by using the Theory of Meaningful Learning (Ausubel), the teacher can prepare and organize lessons, make the assessment of learning and have feedback on teaching practice. The significant learning process takes into account the previous knowledge of the student; the willingness to learn; and how the content fit the problems of personal interest of the students. During the course of Research Methodology for the 'Professor Adjunto do Departamento de Geociências da Universidade Estadual de Londrina (UEL) - ricardolopesfonseca@hotmail.com "Professora Adjunto do Departamento de Geociências, Centro de Ciências Exatas, Universidade Estadual de Londrina (UEL) rosalvi06@gmail.com 
Geography Teaching, a workshop was held on using concept maps, as exemplifying content, Teaching Geography. In groups students collectively built a conceptual map related to the course content. Finally, it was noted that the concept map is a tool that enables the teacher perform the facilitator form of meaningful learning process.

Keywords: Meaningful Learning; Didactics of Geography; Geography Teacher Training; Concept Maps

\section{INTRODUÇÃO}

Os conhecimentos demonstrados no processo de formação inicial do professor de Geografia são sistematicamente considerados complexos pela maior parte dos graduandos, já que se caracterizam pela apropriação de identificações nominais, próprias do saber científico. Sendo assim, se verifica a obrigação de uma ação que provoque o surgimento de didáticas que consigam favorecer o docente na mediação da apoderação do saber.

Faz-se perceptível a carência de planejamentos didáticos que possam ser aplicados pelos futuros professores no ensino da Geografia escolar, sabendo-se que a não compreensão de conhecimentos pelos estudantes do ensino fundamental representa um enorme prejuízo ao crescimento educacional dos mesmos. Em decorrência dessa situação, é necessário que o graduando seja capaz de construir elaborações educacionais em benefícios de um aprendizado significativo.

Dentre as ações possíveis, pode-se indicar o uso de mapas conceituais, um modelo de hierarquia conceitual que, de conformidade com algumas normas de desenvolvimento, propicia reconhecidas vantagens com referência ao tempo disposto para sua execução, revisão da literatura, averiguação da aprendizagem, reprodução da análise, resumo e capacidade intelectual demonstrada pelo estudante na execução principiada por um determinado assunto que se apresenta no momento.

O processo que engloba a preparação de professores visa apresentação de recursos pedagógicos que possam ajudá-los na abordagem dos mais diferentes assuntos desenvolvidos em salas de aula, por meio de planejamentos. O mapa conceitual representa, assim, uma dessas ações estimuladoras, atuando como uma ferramenta importantíssima no crescimento da aprendizagem significativa. 
Por essa razão, o objetivo deste estudo é de verificar se os estudantes em formação inicial, do curso de Geografia, da Universidade Estadual de Londrina, localizada no estado do Paraná (Brasil), matriculados no $3^{\circ}$ ano ( $6^{\circ}$ semestre) atingem a aprendizagem significativa por meio da construção de mapa conceitual. Faz-se importante mencionar que a metodologia desenvolvida envolveu a confecção de mapas conceituais, sugerida por Novak (1972), que defende essa prática como uma base hierárquica dos conhecimentos, construída sob os princípios teóricos da aprendizagem significativa de Ausubel (1968).

\section{A METODOLOGIA E A DIDÁTICA DO ENSINO NA EDUCAÇÃO SUPERIOR}

Tem-se conhecimento que um ensino produtivo é aquele que cumpre com a atribuição escolar na construção do cidadão autônomo e crítico possuidor de capacidade para suplantar as barreiras impostas à sociedade moderna.

Há quatro ações docentes a serem levadas em consideração no Ensino Superior, sendo: a) Prática Docente; b) Avaliação; c) Construção do Conhecimento; d) Relação Professor-Aluno (BAIBICH-FARIA; MENEGHETTI, 2009). Pode-se reconhecer cada uma dessas ações, de conformidade com a discriminação exposta a seguir:

Prática Docente: está relacionada às expectativas de natureza moral e às competências do professor, pelo primeiro destacam-se as qualidades de: respeito e postura democrática; pelo segundo a criatividade, capacidade de inovação e visão crítica e analítica. Avaliação: consiste na capacidade de criticar e ser criticado, sistemática e racionalmente, sem ranços do senso comum. Inclui a auto-avaliação que proporciona ao estudante detectar seus próprios limites. Em suma é o momento de reflexão e auto-análise de posturas e comportamentos. Construção do Conhecimento: tem como ponto de partida a realidade e a constante relação teoria e prática. Relação Professor-Aluno: destaca a forma de tratamento que consiste no respeito, honestidade, amizade e confiança, conceitos que favorecem que o conhecimento seja uma prática humanizada e marcante para os educandos. (BAIBICH-FARIA; MENEGHETTI, 2009, p. 08-09, grifo nosso).

As considerações expostas representam, teoricamente, a metodologia do ensino superior, sendo que, no entanto, não podem ser classificadas como "receitas prontas", permitindo afirmar, inclusive, que discentes organizados por turmas variam 
de uma para outra, de uma unidade ou curso para outro e de uma instituição de ensino para outra.

Faz-se importante que a metodologia do ensino superior esteja sintonizada com as particularidades de cada turma, sabendo-se que não havendo essa aproximação, o ensino se desenvolve de modo automático, não reproduzindo o resultado almejado, desprovido de qualquer ação motivadora. Ressaltando a ligação que envolve o professor e o estudante entende-se que ela é extremamente necessária, pois dela é que resulta a "ética docente" que reconhecerá o docente e o graduando de maneira significativa.

Conforme argumentação de Alcântara (2009, p. 03), "o professor precisa de conhecimentos e habilidades pedagógicas, que podem ser obtidas e aperfeiçoadas mediante leituras e cursos específicos". Esses cursos englobam o que se denomina de "conhecimento e habilidades pedagógicas", instrumentos essencialmente necessários para a construção de uma didática do ensino superior. Esses conhecimentos e habilidades envolvem:

\begin{abstract}
a) Estrutura e Funcionamento do Ensino Superior: o professor deve ser capaz de estabelecer relações entre o que ocorre em sala de aula com processos e estruturas mais amplas. Isto implica a análise dos objetivos a que se propõe o ensino universitário brasileiro, bem como dos problemas que interferem em sua concretização. E exige conhecimentos relativos à evolução histórica das instituições e à legislação que as rege; b)Planejamento de Ensino: a eficiência na ação docente requer planejamento. $O$ professor precisa ser capaz de prever as ações necessárias para que o ensino a ser ministrado por ele atinja os seus objetivos. Isto exige a cuidadosa preparação de um plano de disciplina e de tantos planos de unidade quantos forem necessários; c) Psicologia da Aprendizagem: o que o professor espera de seus alunos é que aprendam o conteúdo da disciplina que pretende lecionar. Neste sentido, conhecimentos de Psicologia poderão ser muito úteis, pois esclarecem acerca dos fatores facilitadores da aprendizagem; d) Métodos de Ensino: a moderna Pedagogia dispõe de inúmeros métodos de ensino. Convém que o professor conheça as vantagens e limitações de cada método para utilizá-los nos momentos e sob as formas mais adequadas; e) Técnicas de Avaliação: não se pode conceber ensino sem avaliação. Não apenas a avaliação no final do curso, mas também a avaliação formativa, que se desenvolve ao longo do processo letivo e que tem por objetivo facilitar a aprendizagem. Assim, o professor universitário precisa estar capacitado para elaborar instrumentos para a avaliação dos conhecimentos e também das habilidades e atitudes dos alunos. (ALCÂNTARA, 2009, p.02, grifo nosso).
\end{abstract}


Esses tópicos, que devem ser considerados como fundamentais para uma didática no ensino superior, são importantes para a preparação completa do professor e também do estudante, sendo que o docente que se beneficia dessas ferramentas didáticas tem por objetivo seu progresso como profissional da educação, demonstrando assim, que sua formação está focada principalmente na realização humana e ao mesmo tempo desenvolvendo o lado técnico e profissional.

\title{
3. A METOdOLOGIA E A DIDÁTICA DO ENSINO DE GEOGRAFIA NA EDUCAÇÃO
}

\section{SUPERIOR}

Ao desenvolver o trabalho com conteúdos geográficos, é necessário que o graduando tenha noção clara do papel da Geografia na escola, no cumprimento de sua função social. Cavalcanti (2006, p. 34) esclarece esse papel desempenhado pela Geografia:

\begin{abstract}
Cabe reafirmar e explicitar a importância da Geografia escolar para a formação geral de cidadãos. Na relação cognitiva de crianças, jovens e adultos com o mundo, o raciocínio espacial é necessário, pois as práticas sociais cotidianas têm uma dimensão espacial. Os alunos que estudam essa disciplina já possuem conhecimentos nessa área oriundos de sua relação direta e cotidiana com o espaço vivido. Sendo assim, o trabalho de educação geográfica é o de ajudar os alunos a analisarem esses conhecimentos, a desenvolverem modos do pensamento geográfico, a internalizarem métodos e procedimentos, de captar a realidade vivida e "apresentada" pela geografia escolar, tendo consciência de sua espacialidade. Esse modo de pensar geográfico é importante para a realização de práticas sociais variadas, já que essas práticas são sempre práticas socioespaciais.
\end{abstract}

Por essa intuição é essencialmente importante guiar-se pelos conhecimentos fundamentais do ideal de espaço. As diferentes espacialidades do mundo moderno reproduzem um panorama constituído por um conjunto de objetos que os sentidos conseguem absorver. O conhecimento desses objetos no espaço não se estabelece com base na simples existência dos mesmos. Essa compreensão está ligada ainda à composição da subjetividade das pessoas ou mesmo da intuição que uma determinada cultura oferece aos objetos de uma paisagem, por exemplo. Assim, a paisagem pode se manifestar de maneira diversificada. Contudo, as paisagens não são 
reproduzidas somente com base nas formas, já que possuem conteúdo, e assim conseguem produzir mobilidade temporal.

Segundo Fonseca (2015, p. 28):

O desenvolvimento do ensino de Geografia tem como fundamento possibilitar ao aluno do ensino regular, a alfabetização geográfica e, somente após essa ação desenvolver a reflexão e análise, bem como a crítica do espaço geográfico. Deve-se permitir aos alunos compreender os saberes geográficos, reconhecendo-os como necessários, o mesmo devendo acontecer por parte do professor.

As modernas ideias do universo consideradas como espaço de atividades individuais e conjuntas, presenciadas pelo indivíduo no seu dia a dia, possibilitam a incidência de práticas referentes ao espaço, que exigem menções à localização, reproduzindo simultaneamente, desenvolvimentos de identificação dos indivíduos ou dos grupos aos quais pertencem.

Em conformidade com Fonseca (2015, p. 36-37):

O professor de Geografia, a escola e a própria disciplina assumem, assim, uma função valorizada dentro do universo da sua própria sociedade. Esse envolvimento tão abrangente se vincula ao objeto da ciência, à atividade desenvolvida pela disciplina na escola e à questão pedagógica, que engloba de forma comprometedora a junção de questionamentos que se referem ao objeto, à ciência e aos métodos.

Por essa intuição, entende-se que para estudar as espacialidades do dia a dia é importante que se recorra ao conhecimento daquilo que representa o lugar. Acerca desse conceito, Cavalcanti (2006, p. 36) esclarece:

A identidade é, nesse entendimento, um outro elemento importante do conceito de lugar. Ela é um fenômeno relacional. Seu aparecimento advém de uma interação de elementos, nesse caso de indivíduos com seus lugares, com formas de vida e com os modos de expressão. Implica um sentimento de pertinência com o qual o indivíduo vai se identificando, vai construindo familiaridade, afetividade, quer seja com um bairro, com um estado, uma área.

Outro aspecto que deve ser levado em consideração com referência ao conceito de lugar, envolve a ligação estabelecida entre o local com o global. É comum o pensamento de que, ao lecionar o ensino geográfico, valorize-se a pesquisa das espacialidades vivenciadas pelo discente, sob o pretexto de que o crescimento da 
aprendizagem poderia ser "mais fácil" e que os locais situados em áreas distantes seriam "mais difíceis" de se proporcionar um ensino de qualidade.

Considerando-se essa situação, reproduziu-se no ensino geográfico uma metodologia orientada no sentido de que, nas primeiras fases de escolaridade, ensina-se conhecimentos referentes à casa e à escola e, posteriormente, volta-se para o bairro, para o estudo, para o país, o mundo etc. Essa metodologia de ensino geográfico fundamenta-se no conceito de "círculo concêntrico", no qual o "eu" representa o eixo referencial para o desenvolvimento da aprendizagem e, assim, consiga abranger locais vistos como mais "complexos", conforme o aluno vai aperfeiçoando seu crescimento intelectual, desenvolvendo sua aprendizagem.

As diversas aproximações teóricas e epistemológicas que reconhecem a Geografia como sendo um espaço do saber e, também, como disciplina escolar conseguem favorecer a incidência de diretrizes para a construção de uma Didática Crítica. Seria uma didática na qual as aprendizagens e as considerações se mostram coerentes com a construção cidadã e libertadora dos estudantes. Sendo assim, haveria imensas probabilidades de se construir uma sociedade mais ética, mais justa e respeitosa quanto às diversidades que determinam os locais e a vida social na atualidade.

No ensino de Geografia, muitos estudiosos têm difundido relevantes bases epistêmicas para a área, as quais têm desenvolvido ofertas metodológicas concretas, beneficiando o ensino geográfico. Nessa situação é preciso demonstrar fundamentos vistos como críticas mais incidentes na Geografia Escolar da atualidade.

A este respeito Pontuschka et al. (2009, p. 97):

[...] é importante que o professor desenvolva a capacidade de utilizá-los como instrumentos para desvendar e compreender a realidade do mundo, dando sentido e significado à aprendizagem. À medida que os conteúdos deixam de ser fins em si mesmos e passam a ser meios para a interação com a realidade, fornecem ao aluno os instrumentos para que possa construir uma visão articulada, organizada e crítica do mundo.

Cavalcanti (2005) e Souza (2009) representam alguns estudiosos da área que tem reconhecido e valorizado as contribuições prestadas por Vygotsky na construção 
de um pensamento espacial crítico à Geografia Escolar. As lógicas vygotskyanas no ensino geográfico se mostram quando se reconhecem os espaços das atividades cotidianas dos alunos como fundamento para a realização de uma aprendizagem crítica.

Vygotsky (2004, p. 67) defende que "a educação se faz através da própria experiência do aluno, a qual é inteiramente determinada pelo meio, e nesse processo o papel do mestre consiste em organizar e regular o meio." Esse estudioso emite críticas quanto à expectativa tradicional do ensino, sabendo que pela qual o professor repassa os assuntos e o discente "aprende" sem, no entanto, ter a certeza de acontecer a internalização. O autor ressalta, ainda, que a garantia dessa apreensão é resultado da experiência do estudante, que se distingue como componente essencial da aprendizagem, além da importância que representa o meio no desenvolvimento do processo. Ele reconhece a importância do papel exercido pelo professor, na intermediação desse crescimento, e da própria escola como local apropriado para a promoção de aprendizagens diversas dos demais processos educativos. As aprendizagens decorrentes do desenvolvimento educativo escolar representam uma das preocupações de Vygotsky (2001; 2004).

A aplicação de elementos da linguagem como componente social será melhor conduzida se o processo de mediação favorecer uma aproximação mais adequada das experiências desenvolvidas. Para essa realização ser possível, a ideia de Zona de Desenvolvimento Proximal (ZDP) se constitui num importante resumo vygotskyano do desenvolvimento, apto para apropriar e internalizar as composições do entorno sociocultural. Por ZDP considera-se a distância existente entre o nível do desenvolvimento atual de uma pessoa, estabelecida por atribuições que ela consegue solucionar de forma independente, e o grau do possível crescimento decorrente de mediações (VYGOTSKY, 2004).

Por essa intuição, entende-se como abordagem crítica aquela capaz de favorecer o estudante no entendimento das diferentes espacialidades que ela 
compõe, como por exemplo, do local vivido, do seu dia a dia, das ligações socioespaciais nas quais se inclui, e tantas outras situações. É muito importante que essas espacialidades estejam em sintonia, por meio do pensamento com outras espacialidades globais.

A reprodução de um pensamento espacial no momento da aproximação decorrerá da apropriação das considerações essenciais da Geografia, tais como: paisagem, lugar, território e região, como também de temas geográficos relevantes para a fundamentação desse ideal, como por exemplo, o meio ambiente, o urbano e o agrário.

Um direcionamento voltado para o crescimento de um ideal geográfico resulta, também, da aprendizagem desses conhecimentos e de temas em diferentes classificações de análise, pelas quais se reproduz uma ligação entre as espacialidades sistematizadas pelo saber geográfico e as aptidões demonstradas pelo estudante no dia a dia. Para essa realização se efetivar é importante que o professor tenha clareza metodológica e, assim, consiga intermediar essa concepção de aprendizagem.

Contudo, cabe ressaltar que para se realizar os processos de ensino e de aprendizagem são diferentes entre crianças (na educação básica) e adultos (neste caso, no ensino superior), sendo que aborda-se a concepções da Pedagogia na primeira e da Andragogia na segunda. Referir-se à metodologia no ensino superior e não mencionar a Andragogia representa o mesmo que falar em educação básica sem fazer referência à Pedagogia.

\section{CONCEPÇÕES ACERCA DA ANDRAGOGIA}

A andragogia é técnica de ensinar conhecimentos aos adultos, sendo que esse termo foi utilizado pela primeira vez no ano de 1883, por Xander Kapp. A andragogia se constitui por quatro tópicos fundamentais, de acordo com as necessidades demonstradas pelos adultos, sendo elas: "1- Querem entender por que têm de 
aprender algo; 2- Preferem aprender o que os ajudará a solucionar seus problemas; 3Aprendem melhor quando estudam assuntos que sejam de valor imediato; 4Precisam aprender experimentalmente" (BELLAN, 2005, p.20, 22).

Os pontos essenciais de aprendizagem de adultos expostos acima distinguem e apontam a direção correta para o método andragógico. Assim, fica evidenciado que a aprendizagem de adultos, sem nenhuma dúvida precisa ser construída de modo significativo e beneficiada por uma linguagem útil, disposta por experiências adquiridas pelos estudantes como ação principal para a reprodução do conhecimento e da pesquisa.

Nos cursos universitários, geralmente recebemos adolescentes como calouros e liberamos adultos como bacharelandos. [...]. Precisamos encontrar um meio termo, onde as características positivas da Pedagogia sejam preservadas e as inovações eficientes da Andragogia sejam introduzidas para melhorar o Processo Educacional. (CAVALCANTI, 2009 p. 06).

Faz-se possível afirmar, assim, que o progresso do crescimento educacional depende de modo especial de uma ação harmoniosa envolvendo andragogia e pedagogia, possibilitando, portanto, que os cursos de educação superior não se constituam em algo "maquinificado" e, em decorrência desse fato, "codificando" as ações interativas de ensino e de aprendizagem e professor-estudante-professor.

De conformidade com Teixeira (2009, p. 01) são conhecidas oito práticas essencialmente importantes aos professores de adultos, podendo ser destacadas quatro entre elas, sendo "- Compreender a situação global em que o Processo Educacional se insere; - Saber colocar-se no lugar do aluno; - Escolher os métodos mais eficazes para a situação [...]; - Conhecer e aperfeiçoar-se na Andragogia". Em todas essas quatro ações, o conceito principal que se apresenta é, certamente, a priorização de um ensino que se desenvolva fundamentado na "experiência" não só do professor, mas também do discente. 


\section{A TEORIA DA APRENDIZAGEM SIGNIFICATIVA: O USO DOS MAPAS}

\section{CONCEITUAIS}

A Teoria da Aprendizagem Significativa (TAS) é defendida em estudo desenvolvido por David Ausubel, como sendo a sustentação intelectual dos indivíduos, já que consegue se desenvolver de forma organizada, favorecendo o crescimento da aprendizagem. Sendo assim, um determinado conhecimento pode estar inteiramente relacionado a um outro saber, considerado mais simples, que venha Ihe completar.

De acordo com esse raciocínio, entende-se ser totalmente desproposital um esforço que vise reproduzir uma aprendizagem que não esteja vinculada ao crescimento cognitivo da pessoa. Uma das ações necessariamente importantes para a solidificação da Aprendizagem Significativa (AS) é certamente a existência de uma ligação que consiga envolver o conhecimento já adquirido e o que se apresenta como algo novo.

Dessa maneira, o conhecimento novo representa uma valorização para o indivíduo, e aquele previamente adquirido se torna mais completo e diferenciado (MOREIRA, 1998). O mesmo estudioso defende ainda que o conhecimento prévio possibilita a diferença que vai ocasionar o crescimento da aprendizagem. Dessa forma, as pessoas só conseguirão absorver saberes novos de forma significativa se puderem adquirir também conhecimentos já determinados anteriormente.

Ainda, de conformidade com Moreira (1998), o conhecimento se sugestiona àquele já adquirido, e,

[...] a aprendizagem é dita significativa quando uma nova informação (conceito, idéia, proposição) adquire significados para o aprendiz através de uma espécie de ancoragem em aspectos relevantes da estrutura cognitiva preexistente do indivíduo, isto é, em conceitos, idéias, proposições já existentes em sua estrutura de conhecimentos (ou de significados) com determinado grau de clareza, estabilidade e diferenciação (MOREIRA, 1998, p.147).

A atividade que envolve a ligação do conhecimento prévio com os novos precisa estar fundamentada nos conhecimentos já absorvidos pelos estudantes, são 
os conhecidos como subsunçores. Quando acontece a realização da aprendizagem, novos subsunçores são reproduzidos, favorecendo a atribuição de importância de novos conhecimentos.

A realização de uma aprendizagem reconhecidamente importante requer uma vinculação construída pelos alunos envolvendo os saberes prévios - os subsunçores e novos, devendo acontecer de maneira justa, agrupada em seu princípio intelectual. Essa relação deve ser construída de forma simbólica, beneficiada por uma palavra, um cenário, ou mesmo, favorecida por uma situação já conhecida pelos estudantes, enfim, por algum conhecimento já estabelecido.

Nessa mesma intuição, David Ausubel (1988, p. 61) emite a seguinte opinião:

La esencia del proceso del aprendizaje significativo reside en que ideas expresadas simbólicamente son relacionadas de modo no arbitrario, sino sustancial (no al pie de la letra) con lo que el alumno ya sabe, seña la demente algún aspecto esencial de su estructura de conocimientos (por ejemplo, una imagen, un símbolo ya con significado, un contexto o una proposición). (AUSUBEL, 1988, p. 61).

Ausubel defende que o estudante consegue desenvolver um papel de importância fundamental na destinação de significados dos assuntos, devendo optar por aquilo que está sendo oferecido pelo professor, ou encontrar aptidões para agregar as matérias esplanadas em sala de aula às suas experiências e conhecimentos prévios:

El aprendizaje significativo presupone tanto que el alumno manifiesta una actitud hacia el aprendizaje significativo; es decir, una disposición para relacionar, no arbitraria, sino sustancialmente, el material nuevo con su estructura cognoscitiva, como que el material que aprende es potencialmente significativo para él, especialmente relacionable con su estructura de conocimiento, de modo intencional y no al pie de la letra (AUSUBEL, 1988, p. 62).

No entanto, é possível entender que a maneira como os conteúdos desenvolvidos em salas de aula representará uma ação relevante na estimulação, possibilitando que o estudante possa aprender de modo correto e necessário.

Comparando as práticas de ensinar e instruir, Antunes (2008), defende que a primeira tem uma importância reconhecidamente maior, considerando-se que o professor ao se dispor a instruir seus discentes acabará excluindo, mesmo que 
parcialmente, a capacidade de criação deles, já que essa capacitação criativa está relacionada à ação de repetir procedimentos em situações já estabelecidas previamente. Assim, "ensinar quer dizer ajudar e apoiar os alunos a confrontar uma informação significativa e relevante no âmbito da relação que estabelecem com uma dada realidade, capacitando-o para reconstruir os significados atribuídos a essa realidade e a essa relação" (ANTUNES, 2008, p. 30).

Dessa forma, é possível entender que o crescimento da AS não se constrói apenas com a participação do estudante, dependendo, e muito, do professor, sendo seu envolvimento de reconhecida importância na mediação na construção desse procedimento.

Permite-se afirmar ainda que na AS o conhecimento inédito não poderá reproduzir experiências semelhantes para um grupo de pessoas. O processo de atribuição de significados direcionados aos assuntos deverá se desenvolver de maneira diferente para cada estudante, de acordo com a habilidade intelectual de cada um.

Para se conseguir desenvolver conteúdos que ofereçam a possibilidade de AS, antes de se explanar o conteúdo novo é preciso que o professor identifique conceitos subsunçores já dominados pelos estudantes, e assim, possa ligá-los com o assunto. Esses conhecimentos devem dispor de um reconhecido grau de difusão, fazendo com que os alunos possam, principiando dessa compreensão, relacionar o assunto novo que se expõe naquele momento.

Assim, os Mapas Conceituais (MC) aparecem como uma ferramenta que auxilia no processo de AS. São considerados diagramas de conceitos que representam as ligações e hierarquias construídas entre eles (MOREIRA, 2010). Os MC foram desenvolvidos por Novak, nos Estados Unidos, em 1972, por meio de um programa de pesquisas elaborado pela Universidade de Cornell. Esse programa priorizou a busca de uma compreensão de como as crianças conseguiam dividir conhecimentos em ciências (NOVAK; CANÃS, 2008). Os MC são aplicados como sendo uma linguagem 
que favoreça a descrição e transferência de saberes e suas ligações e, assim, foram, a princípio, reproduzidos para a concretização da AS (AUSUBEL, 1968).

No decorrer das pesquisas, Novak e seus seguidores experimentaram situações embaraçosas na busca por reconhecer as reciprocidades distintas desenvolvidas sob o entendimento de saberes científicos demonstrados pelas crianças entrevistadas. Com base na obrigação de se encontrar uma melhor direção para representar as vinculações conceituais que essas crianças faziam de sua percepção de ciências, desenvolveu-se a ideia de reproduzir esse conhecimento sob a forma de MC. Logo, eles se transformavam num utensílio relevante para as pesquisas, sendo que também foram desenvolvidas diversas atribuições para eles.

Esses MC são demonstrados como um conceito, comumente escrito em uma ou duas palavras numa figura retangular, podendo estar vinculados a outros conhecimentos possibilitando a criação de frases explicativas ou outras proposições (NOVAK; CANÃS, 2008). Conceitos representam situações observadas em eventos ou objetos, ou mesmo quando se menciona um acontecimento, ou objeto definido por um nome. Esses conhecimentos são organizados de forma hierárquica, principiando do mais geral, conceito mais inclusivo na parte superior para o mais específico, que é reunido ao conhecimento geral. Proposições são argumentações que se referem a algum fato ou objeto que reproduzem uma ligação englobando dois ou mais conhecimento (MOREIRA, 2010). Assim, é possível se desenvolver relações entremeadas entre conceitos em dois diferentes campos de um mesmo MC.

A reprodução de um MC pode principiar por uma relação de conhecimentos que o professor pede que seus estudantes incluam no seu mapa. Pesquisadores exímios na elaboração de MC indicam como uma das grandes dificuldades na sua realização, a construção de sugestões, isto é, a incidência de frases que reunirão os conhecimentos, proporcionando a criação de vinculações entre eles.

Portanto, é possível afirmar que no momento que o professor consegue propiciar alguns dos conceitos ele não pode, contudo, reduzir a dificuldade que os 
estudantes demonstram na elaboração dos mapas conceituais, mas pode restringir a capacidade criativa destes na classificação dos conceitos.

\section{CONTEXTUALIZAÇÃO E RELATO DE EXPERIÊNCIA}

Considerando o conteúdo exemplificador "A Didática da Geografia", a metodologia aplicada neste trabalho consistiu na realização de cinco etapas:

- $\quad$ concepções prévias dos estudantes;

- $\quad$ fundamentação teórica;

- $\quad$ oficina de Mapa Conceitual;

- discussão teórica do conteúdo exemplificador (Didática da Geografia);

- $\quad$ realização do Mapa Conceitual Coletivo.

Na primeira etapa foi realizada a verificação do conhecimento prévio dos graduandos acerca do significado, bem como da finalidade e pressupostos teóricos que envolvem a construção e uso dos MC enquanto facilitador da aprendizagem significativa. Nesta etapa foi possível realizar um diagnóstico de como os discentes compreendiam a utilização dos MC. No decorrer desta discussão apresentou-se o MC como uma estratégia facilitadora da AS.

$\mathrm{Na}$ segunda etapa foi explicado acerca do surgimento do $M C$, da fundamentação teórica referente a Teoria da Aprendizagem Significativa a qual Novak se baseia.

Na terceira etapa foi realizada uma oficina de MC. Num primeiro momento, de forma manual e, posteriormente, por meio do software Cmap Tools, os graduandos aprendem sobre como construí-los. Nesta etapa, o MC foi apresentado como uma ferramenta que auxilia o docente a identificar o conhecimento prévio do educando e, a partir dessa ação, realizar a mediação do conhecimento.

Na quarta etapa foi realizada a discussão do conteúdo exemplificador para esta análise "Didática da Geografia", com base em textos de apoio para que os graduandos pudessem interagir com o docente. 
Na quinta e última etapa, os graduandos, em grupo, num total de quatro grupos com seis alunos em cada, realizaram a construção de seus MC com base no tema discutido na etapa anterior. Essa discussão, promovida pelo grupo após a leitura dos textos e diálogos com o docente e os demais colegas, proporcionou uma significativa troca de informações entre todos.

Pode-se afirmar pelas atividades desenvolvidas em grupo e, com o docente sendo parte do processo de mediação pedagógica, que houve promoção da interação social, percebendo-se indícios de Aprendizagem Significativa. Na figura 1 é possível constatar o resultado obtido de um dos grupos de alunos.

O MC inicia-se com os princípios básicos que envolvem a Didática da Geografia tendo como ponto de partida as concepções de Vygotsky e Bachelard. Os graduandos ressaltaram no mapa que para o primeiro autor existe um conjunto de acepções conceituais que direcionam a Didática para as experiências cotidianas, a internalização dos conceitos geográficos e a vivência dos estudantes. No caso de Bachelard, a Didática está direcionada ao conhecimento científico e ao erro. Enquanto perspectiva didática e construção de conceitos por parte dos próprios discentes, observa-se a construção de conhecimento por meio de um pensamento autônomo.

O MC por si demonstra vários detalhes a respeito das reflexões feitas em sala de aula, contudo, vale mencionar que discussões feitas durante a elaboração do mapa asseveram ao docente atento aos comentários que surgiam, um caminho metodológico promissor no sentido de alcançar AS por parte do estudante.

Será a partir das orientações metodológicas que as ideias dos autores passarão por um entroncamento por seus aparatos semelhantes, neste caso, a partir do estabelecimento da relação que os graduandos fazem das categorias principais do Espaço Geográfico (Paisagem, Lugar, Região e Território) articuladas pelas categorias secundárias (Sociedade e Natureza), de modo que se chega a uma construção direta (consciência crítica e construção do conhecimento) e indireta (práticas sociais como possibilidades para mudar a realidade do espaço vivido) da Didática que envolve, portanto, a Formação Inicial do Professor de Geografia. 
Figura 01 - Mapa Conceitual elabora coletivamente pelos alunos do curso de graduação em geografia, da Universidade Estadual de Londrina-PR.

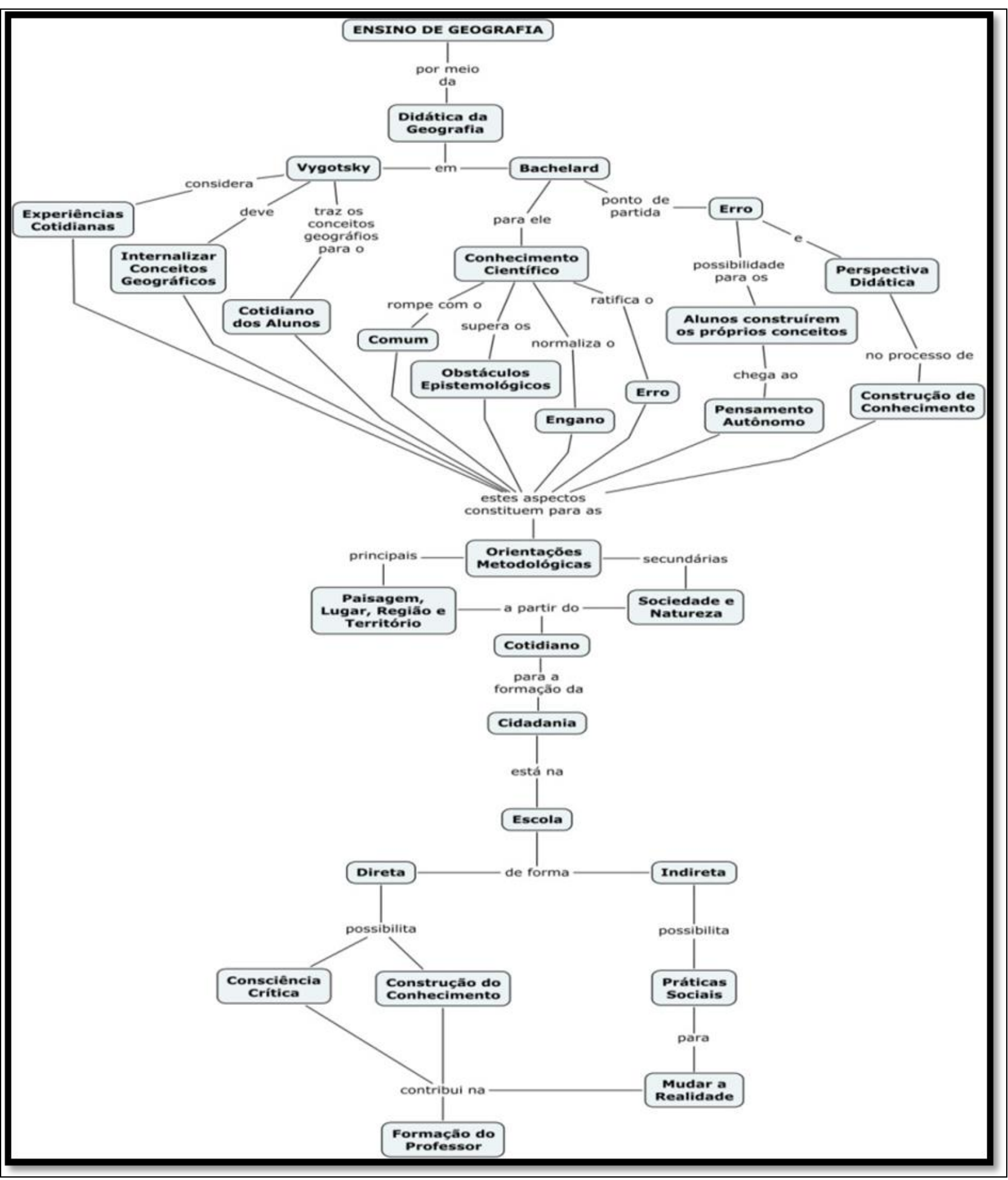

Org: os autores. 
Este tipo de ação, em grupo, instiga a participação do discente, facilita a circulação de informações, auxilia na elaboração de argumentação crítica, e permite, ainda, a troca de ideias e opiniões, possibilitando a prática da colaboração para a obtenção de um fim comum: a aprendizagem. Por fim, acredita-se que o MC é uma ferramenta capaz de demonstrar as evoluções conceituais de um educando.

\section{CONSIDERAÇÕES FINAIS}

A aprendizagem de conteúdos inéditos exige mudanças de ideias semelhantes às verificadas na construção do crescimento científico, sabendo-se que os pensamentos ou sugestões, até então em vigor, são agora aperfeiçoadas. Dessa forma, no transcorrer do processo de aprendizagem tem-se por objetivo que o estudante deixe de lado considerações de senso comum, substituindo-as por ideias assimiladas sob o ponto de vista científico.

Para que essa realidade aconteça é interessante que seja reproduzida oportunidades que possam ajudar o graduando na apreensão dos saberes pesquisados no decorrer da sua formação em Geografia, beneficiados por uma eficiente ação inovadora de ensino, representada pelos MC, aplicação da TAS de Ausubel, defendida por Novak.

Esses MC podem ser considerados como elementos relevantes na construção e apoderação do saber. Podem ser reconhecidos, também, como sendo opção ainda pouco dominada, no decorrer da graduação, como sendo componentes de identificação do saber que o graduando possui, de percepção visual e, de modo simplificado, de um determinado assunto, como um recurso para avaliação.

Sabe-se que cada indivíduo é possuidor de sua estrutura intelectual específica, como resultado de um crescimento ininterrupto de desenvolvimento próprio, devendo sustentar suas ideias, vivências e conhecimentos. Ao construir-se individualmente um MC vinculado a um conhecimento e como conceito ou pensamentos a ele se agrupam. 
Entende-se, também, que um MC não é autoexplicativo, e, por essa razão é interessante que esta explicação se dê por meio do seu autor. Portanto, ele esclarece e expõe seus dados psicológicos. Se o $M C$ é reproduzido conjuntamente, os significados deverão ser detalhados e discutidos no período de seu desenvolvimento; tal fato não acontecendo, torna-se praticamente impossível a construção do mesmo. Tanto a construção individual como a construção coletiva são experiências necessárias e interessantes do ponto de vista da aprendizagem.

Entende-se assim que a partir do momento que os discentes demonstram ter adquirido conhecimento suficiente das composições dos mapas, eles conseguem também reconhecer a sua importância e, deste modo, conseguem dominá-los, possibilitando a transposição deste recurso para a sala de aula, na educação básica, evoluindo gradativamente, ou seja, confeccionando-os cada vez mais bem desenvolvidos.

Deve-se lembrar que o docente é responsável por esse progresso, não só daquilo que se refere à reprodução de sua ferramenta de trabalho, que os MC representam, mas também por exercer a sua atribuição mediadora, sendo assim o elemento principal do crescimento de toda a metodologia desenvolvida em sua atividade realizada com os graduandos do $3^{\circ}$ ano (6 $6^{\circ}$ semestre), curso de Geografia, da Universidade Estadual de Londrina, localizada no estado do Paraná (Brasil).

Por fim, a oficina destinada aos MC tem sua significação reconhecida, já que os MC representam uma opção a mais dentro da atividade pedagógica atribuída ao professor, sendo uma ação estratégica de ensino e de aprendizagem à sua disposição, permitindo-Ihe emitir um diagnóstico referente aos seus discentes, acerca do conteúdo pesquisado, observando suas dificuldades e, assim, estabelecendo ações que possam ajudar na construção e crescimento do saber.

\section{REFERÊNCIAS}

ALCÂNTARA, P. Didática do Ensino Superior. Disponível em <http://www.scribd.com/doc/6935436/Didática-EnsinoSuperiorPaulo-Alcântara>. Acesso em: 05 fev. 2015. 
ANTUNES, C. Professores e professauros: reflexões sobre a aula e práticas pedagógicas diversas. Petrópolis (RJ): Vozes, 2009.

AUSUBEL, D. P. Psicologia educativa: un punto de vista cognoscitivo. México, Trillas, 1988. BAIBICH - FARIA, T. M; MENEGUETTI, F. K. Metodologia do Ensino Superior ou Ética da Ação do Professor. Curitiba, 2009. 16p.

BELLAN, Z, S. Andragogia em Ação: Como Ensinar Adultos sem se tornar Maçante. 2.ed. Santa Bárbara d'Oeste. Socep. 2005.

CAVALCANTI, L. de S. Cotidiano, Mediação pedagógica e formação de conceitos: uma contribuição de Vygotsky ao ensino de Geografia. Caderno Cedes. v. 25, n. 66, maio/ago, 2005.

CAVALCANTI, L. de S. Bases teórico-metodológicas da Geografia: uma referência para formação e a prática de ensino. In: práticas em Geografia. Goiânia: Vieira, 2006. (org.). Formação de professores: concepções e

CAVALCANTI, R. A. Andragogia: A Aprendizagem nos Adultos. Disponível em <http://www.rau-tu.unicamp.br/nou-rau/ead/document/?view=2>. Acesso em 03 fev. 2015.

FONSECA, Ricardo Lopes. Avaliação da Preparação de Graduandos de Geografia para a Inclusão de Alunos com Necessidades Educacionais Especiais. 2015. $183 \mathrm{fls}$. Tese (Doutorado em Geografia) - Universidade Estadual de Londrina. Londrina, 2015.

MOREIRA, M. A. Mapas conceituais e aprendizagem significativa. Cadernos de Aplicação, Porto Alegre, v. 11, n. 2, p. 143-156, 1998.

MOREIRA, M. A. Teorias de Aprendizagem. 3. Ed. São Paulo: Editora Pedagógica e Universitária, 2010.

NOVAK, J.D.; CAÑAS, A. J. The Theory Underlying Concept Maps and How to Construct and Use Them.Technical Report IHMC CmapTools. Florida Institute for Human and Machine Cognition (IHMC), 2008.Disponível em: <http://cmap.ihmc.us/Publications/ResearchPapers/TheoryUnderlyingConceptMaps.pdf>. Acesso em: 09 fev. 2015.

PONTUSCHKA, N. N.; PAGANELLI, T. I.; CACETE, N. H. A Formação Docente e o Ensino Superior. In: PONTUSCHKA, N. N.; PAGANELLI, T. I.; CACETE, N. H. Para Ensinar e Aprender Geografia. $3^{a}$ Ed. - São Paulo: Cortez, 2009. - (Coleção docência em formação. Série Ensino Fundamental). pp. 383.

SOUZA, V. C. de. $\mathbf{O}$ processo de construção do conhecimento geográfico na formação do professor de Geografia.Tese (Doutorado em Geografia), IESA/UFG, Goiânia, 2009. 
TEIXEIRA, G. Andragogia: as 8 práticas fundamentais do professor de adultos. Disponível em: <www.serprofessoruniversitario.pro.br/ler.php?modulo=1\&texto=2>. Acesso em: 04 fev. 2015.

VYGOTSKY, L. S. Psicologia Pedagógica. São Paulo: Martins Fontes, 2004. 